\title{
Genetic evaluation using multi-trait and random regression models in Simmental beef cattle
}

\author{
R.R. Mota ${ }^{1}$, L.F.A. Marques $^{2}$, P.S. Lopes ${ }^{1}$, L.P. da Silva ${ }^{1}$, F.R.A. Neto ${ }^{3}$, \\ M.D.V. de Resende ${ }^{4,5}$ and R.A. Torres ${ }^{1}$ \\ ${ }^{1}$ Departamento de Zootecnia, Universidade Federal de Viçosa, \\ Viçosa, MG, Brasil \\ ${ }^{2}$ Departamento de Zootecnia, \\ Centro de Ciências Agrárias da Universidade Federal do Espírito Santo, \\ Alegre, ES, Brasil \\ ${ }^{3}$ Departamento de Zootecnia, Faculdade de Ciências Agrárias e Veterinárias, \\ Universidade Estadual Paulista "Júlio de Mesquita Filho", \\ Jaboticabal, SP, Brasil \\ ${ }^{4}$ Embrapa Florestas, Colombo, PR, Brasil \\ ${ }^{5}$ Departamento de Engenharia Florestal, Universidade Federal de Viçosa, \\ Viçosa, MG, Brasil \\ Corresponding author: R.R. Mota \\ E-mail: rreismota@hotmail.com
}

Genet. Mol. Res. 12 (3): 2465-2480 (2013)

Received August 23, 2012

Accepted January 26, 2013

Published July 24, 2013

DOI http://dx.doi.org/10.4238/2013.July.24.2

\begin{abstract}
The Brazilian Association of Simmental and Simbrasil Cattle Farmers provided 29,510 records from 10,659 Simmental beef cattle; these were used to estimate (co)variance components and genetic parameters for weights in the growth trajectory, based on multi-trait(MTM) and random regression models (RRM). The (co)variance components and genetic parameters were estimated by restricted maximum likelihood. In the MTM analysis, the likelihood ratio test was used to determine the significance of random effects included in the model and to define the most appropriate model. All random effects were significant and included in the final model. In the RRM analysis, different adjustments
\end{abstract}


of polynomial orders were compared for 5 different criteria to choose the best fit model. An RRM of third order for the direct additive genetic, direct permanent environmental, maternal additive genetic, and maternal permanent environment effects was sufficient to model variance structures in the growth trajectory of the animals. The (co)variance components were generally similar in MTM and RRM. Direct heritabilities of MTM were slightly lower than RRM and varied from 0.04 to 0.42 and 0.16 to 0.45 , respectively. Additive direct correlations were mostly positive and of high magnitude, being highest at closest ages. Considering the results and that pre-adjustment of the weights to standard ages is not required, RRM is recommended for genetic evaluation of Simmental beef cattle in Brazil.

Key words: Body weight; (Co)variance components; Heritability; Growth trajectory

\section{INTRODUCTION}

The genetic evaluation of beef cattle in Brazil has been performed using animal models by mixed model methodology, which routinely uses multi-trait models (MTM) to predict breeding values of animals (Marques et al., 1999, 2001; Nobre et al., 2003). Random regression models (RRM) (Henderson Jr., 1982; Laird and Ware, 1982) are an alternative to longitudinal data analysis (Dias et al., 2006; Albuquerque and El Faro, 2008; Sánchez et al., 2008).

In the MTM, animals are evaluated at different ages for weight along the growth curve, due to the collection of the records of weights at different ages. Thus, in most cases, the records of weights are taken at specific intervals and pre-adjusted for standard ages, and those that are outside the intervals are disregarded. The use of adjusted weights to standard ages or the elimination of those that are outside the pre-determined age intervals can lower the accuracy of predicted breeding values of animals (Meyer, 2004).

In RRM, the models used in genetic evaluation of animals involve continuous functions to describe both fixed and random effects. The breeding values are predicted by continuous functions of deviations from each animal (taken as random) in relation to average curve (taken as fixed). The application of RRM allows the utilization of all available records, so the pre-adjustment of the weights to the standard ages is not necessary.

A major criticism of RRM is that in the extremes of the age range or when the data are insufficient, the estimated parameters may not be accurate (Meyer, 1999). This fact is common in beef cattle, since the data collection is sequential and because observations related to advanced ages of animals are scarce, resulting in less accurate parameter estimates for these ages. One way to evaluate the quality of the parameters of RRM is to compare their estimates with those obtained from the MTM. Although estimates of MTM could be bias or less accurate in relation to the subjacent model due to pre-adjustments to standard ages, they tend to be less affected by extreme trajectory conditions.

Genetic evaluations in beef cattle of the Simmental breed in Brazil have been conducted in MTM, providing estimates in specific ages, comprising birth, weaning, yearling, and final weights. However, nowadays, it is possible to estimate (co)variance components and genetic parameters using RRM, due to the development of algorithms and software able to 
process genetic analysis of longitudinal data.

Considering these facts, the aims of this study were as follows: to estimate orders of fixed regression curve and random effects of (co)variance functions in the description of the growth trajectory, using RRM fitted by Legendre polynomials; to estimate (co)variance components and genetic parameters for weights along the growth curve of beef cattle of the Simmental breed in Brazil using MTM and RRM; to compare the estimates of (co)variance components and genetic parameters obtained in both models to determine their suitability in the utilization of RRM to describe the growth trajectory of animals.

\section{MATERIAL AND METHODS}

The database analyzed in this study referred to body weights of Simmental cattle from 485 farms provided by the Brazilian Association of Simmental and Simbrasil Cattle Farmers (ABCRSS - Associação Brasileira de Criadores das Raças Simental e Simbrasil) located in the city of Cachoeiro de Itapemirim, State of Espírito Santo, Brazil. The weight records used were from the 60th to the 819th days of age from animals born between 1974 and 2006.

Two data files were prepared for analysis: one was used in the analysis with MTM and two-trait analysis, and the other was used in the analysis with RRM. Both files were composed of the same animals. The animals from the reproductive technique of embryo transfer, and the calves from dams whose ages at birth were less than 700 days and more than 2340 days were excluded from the analysis, to enable the study of maternal effects.

In both analyses, the contemporary group defined by animals of the same sex, year, season ( 1 = January to March, 2 = April to June, 3 = July to September, 4 = October to December) and farm of birth was as the fixed effect while age classes (in days) of the cows at calving (class 1: from 700 to 1109; class 2: from 1110 to 1519; class 3: from 1520 to 1919, class 4: from 1920 to 2340) were considered as covariate in linear and quadratic effect. Contemporary groups with less than 3 observations were excluded from the analysis.

The data file for MTM analysis consisted of adjusted weights for ages at 100 (W100), 205 (W205), 365 (W365), 450 (W450), 550 (W550), and 730 (W730) days. Therefore, for adjustments of W100, W205, W365, W450, W550, and W730, the weights used were between 60 and 149, 150 and 299, 300 and 419, 420 and 499, 500 and 619, 620 and 819 days of age, respectively.

The weights were adjusted by the formula:

$$
\mathrm{SWi}=\mathrm{Wj}+[(\mathrm{Wi}-\mathrm{Wj}) /(\mathrm{Di})](\mathrm{Ai}),
$$

(Equation 1)

where $S W i$ is the standard weight for age $\mathrm{i} ; \mathrm{Wi}$ is the observed weight close to the standard age $A i ; W j$ is the previous weight observed at the weight $W i ; A i$ is the standard age, $\mathrm{i}=1$ (100 days), ..., 6 (730 days); Di is the age (in days) of observation $W i$.

Records of weights outside the intervals given by the average of the contemporary group were excluded - more or less 3 standard deviations. After the restrictions, MTM consisted of 29,510 records of 10,659 animals, calves of 1289 sires, and 7332 dams. Descriptive statistics of the data files for multi-trait analysis is demonstrated in Table 1.

The data file for the random regression analysis was composed of the same weight records of the animals used in the multi-trait analysis, but not adjusted. Tables 2 and 3 present, respectively, the descriptive statistics and file structure in relation to the number of records per animal. The number of records and the average body weight for each age are presented in Figure 1. 
Table 1. Description of data for pre-adjusted weights at 100 (W100), 205 (W205), 365 (W365), 450 (W450), 550 (W550), and 730 (W730) days old of the data file for analysis via multi-trait models.

\begin{tabular}{lcrccccccc}
\hline Weight & N & Sire & Dams & CG & Mean $(\mathrm{kg})$ & SD $(\mathrm{kg})$ & CV $(\%)$ & Min $(\mathrm{kg})$ & Max $(\mathrm{kg})$ \\
\hline W100 & 6236 & 975 & 4606 & 1192 & 130.76 & 40.26 & 30.79 & 49.10 & 319.55 \\
W205 & 7938 & 1119 & 5740 & 1389 & 222.56 & 60.38 & 27.13 & 88.84 \\
W365 & 6070 & 961 & 4504 & 1208 & 338.47 & 83.77 & 24.75 & 156.63 \\
W450 & 3666 & 738 & 3458 & 960 & 380.5 & 90.34 & 23.74 & 177.26 & 639.57 \\
W550 & 3468 & 693 & 2790 & 902 & 441.1 & 104.51 & 23.69 & 196.5 & 793.12 \\
W730 & 2132 & 505 & 1815 & 636 & 562.72 & 141.59 & 25.16 & 238.05 & 1108.52 \\
\hline
\end{tabular}

$\mathrm{N}=$ number of observations; $\mathrm{CG}=$ contemporary groups; $\mathrm{SD}=$ standard deviation; $\mathrm{CV}=$ coefficient of variation; Min $=$ minimum value; Max $=$ maximum value.

Table 2. Description of data for weights along the growth curve of the data file for analysis via random regression models.

\begin{tabular}{|c|c|c|c|c|c|c|}
\hline Age (days) & $\mathrm{N}$ & Mean $(\mathrm{kg})$ & SD (kg) & CV (\%) & $\operatorname{Min}(\mathrm{kg})$ & $\operatorname{Max}(\mathrm{kg})$ \\
\hline $60-149$ & 6236 & 129.73 & 29.89 & 23.04 & 63.57 & 218.54 \\
\hline $150-299$ & 7938 & 220.20 & 49.45 & 22.45 & 106.33 & 352.85 \\
\hline $300-419$ & 6070 & 331.93 & 77.03 & 23.20 & 166.80 & 550.49 \\
\hline $420-499$ & 3666 & 385.17 & 89.39 & 23.21 & 183.96 & 641.73 \\
\hline $500-619$ & 3468 & 438.03 & 100.26 & 22.89 & 210.5 & 758.35 \\
\hline $620-811$ & 2132 & 530.44 & 125.09 & 23.58 & 250.93 & 955.15 \\
\hline
\end{tabular}

For abbreviations, see legend to Table 1.

Table 3. Structure of file for random regression analysis with relation to the number of records per animal.

\begin{tabular}{lcr}
\hline Analysis of data & Number of animals & Percentage \\
\hline Total & 10,659 & 100.00 \\
Animals with 1 record & 2,915 & 27.35 \\
Animals with 2 records & 2,401 & 22.53 \\
Animals with 3 records & 1,938 & 18.18 \\
Animals with 4 records & 1,624 & 15.23 \\
Animals with 5 records & 1,203 & 11.29 \\
Animals with 6 records & 578 & 5.42 \\
\hline
\end{tabular}

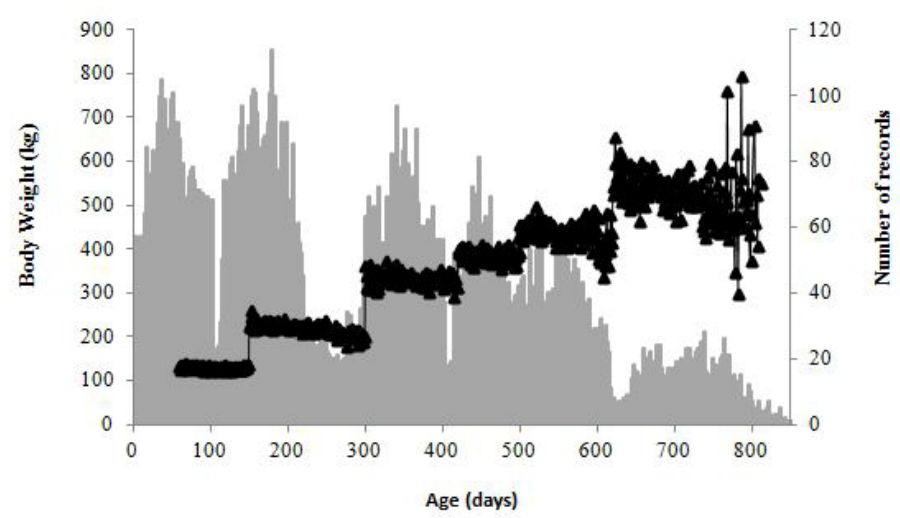

Figure 1. Number of records (gray bars) and average body weight (black triangles) for each age in the data file random regression model. 
The organization and consistency analysis of the data files were performed using the SAS software (SAS, 2004); the estimation of (co)variance and genetic parameters for both analyses with MTM and RRM were performed by restricted maximum likelihood developed by Patterson and Thompson (1971), and obtained by the utilization of the Wombat software, developed by Meyer (2007).

The pedigree of animals was renumbered using the Renped software, developed by Silva (2011). The numerator relationship matrix used in both multi-trait and random regression analysis contained 41,904 animals.

\section{MTM}

First, single-trait analysis was performed for the 6 traits, using 3 different models, which differed in random effects, from the most complete (direct additive genetic effect, maternal additive genetic, and maternal permanent environmental) to the reduced model (direct additive genetic effect). With type 1 error probabilities of 1 and $5 \%$, the likelihood ratio test (LRT) was used to determine the significance of the random effects in the model and define the most suitable models for two-trait analysis.

Afterwards, $\mathrm{N}=\mathrm{p}(\mathrm{p}-1) / 2$ two-trait analysis was carried out where: $n$ is the number of analyses performed and $p$ is the number of traits, totaling 15 combinations (W100-W205, W100-W365, W100-W450, W100-W550, W100-W730, W205-W365, W205-W450, W205W550, W205-W730, W365-W450, W365-W550, W365-W730, W450-W550, W450-W730, W550-W730) in the estimation of (co)variance components and genetic parameters.

The animal model was described in matrix notation as follows:

$$
\mathrm{y}=\mathrm{X} \beta+\mathrm{Z}_{1} \mathrm{~d}+\mathrm{Z}_{2} \mathrm{~m}+\mathrm{Z}_{3} \mathrm{mp}+\mathrm{e}
$$

where $y$ is a vector of observations; $\beta$ is a vector of fixed effects; $d$ is a vector of random direct additive genetic effects; $m$ is a vector of random maternal additive genetic effects; $m p$ is a vector of random maternal permanent environmental effects; $X$ is an incidence matrix for fixed effects; $Z_{1}, Z_{2}$ and $Z_{3}$ are incidence matrices, respectively, to the random effects, direct additive genetic, maternal additive genetic, and maternal permanent environmental; and $e$ is a vector of random residual effects.

The following assumptions were made:

$$
E\left[\begin{array}{c}
y \\
d \\
m \\
m p \\
e
\end{array}\right]=\left[\begin{array}{c}
X \beta \\
0 \\
0 \\
0 \\
0
\end{array}\right], V\left[\begin{array}{c}
d \\
m \\
m p \\
e
\end{array}\right]=\left[\begin{array}{cccc}
\mathrm{A} \otimes G_{d} & 0 & 0 & 0 \\
0 & \mathrm{~A} \otimes G_{m} & 0 & 0 \\
0 & 0 & I_{v} \otimes \mathrm{Q} & 0 \\
0 & 0 & 0 & I_{n} \otimes \mathrm{R}
\end{array}\right]
$$

where $G_{d}$ is the matrix of (co)variances of random direct additive genetic effects; $G_{m}$ is the matrix of (co)variances of random maternal additive genetic effects; $Q$ is the matrix of (co) variances of random maternal permanent environmental effects; $R$ is the matrix of (co)variances of residual effects; $A$ is the numerator relationship matrix between the individuals; $I_{v}$ is an identity matrix with order being the number of mothers; $I_{n}$ in an identity matrix with order being the number of observations; and $\otimes$ is the direct product operator. 


\section{RRM}

The RRM can be studied by 2 groups of regression weights, according to the measured ages. The first relates to the fixed regression for the individuals belonging to the same class of fixed effects, and the second is the random one that describes the deviations of each individual in relation to the fixed regression.

The fixed and random regressions were represented by continuous functions, and a RR was adjusted for random effects, direct additive genetic, maternal additive genetic, maternal permanent environmental, and direct permanent environmental, where covariates were described by Legendre polynomials.

The tested fixed regressions were of the order 3,4 or 5 , and the choice was based on the determination coefficient $\mathrm{R}^{2}$. For the direct additive genetic effect, quadratic, cubic, quartic, and quintic polynomials were used, i.e., $\mathrm{k}_{\mathrm{d}}=3,4,5$ and 6 , respectively, where $k$ refers to the order of covariance function. The direct permanent environmental effect was modeled considering polynomials of the second, third, fourth, and fifth degrees, i.e., $\mathrm{k}_{\mathrm{p}}=3,4,5$ and 6 , respectively. Linear, quadratic, and cubic polynomials were used for the maternal additive genetic and of maternal permanent environmental effects, i.e., $\mathrm{k}_{\mathrm{m}}=\mathrm{k}_{\mathrm{mp}}=2,3$ and 4, respectively, where, $k_{d}, k_{p}, k_{m}$, and $k_{m p}$ are the orders of the covariance function, respectively, for the direct additive genetic, direct permanent environmental, maternal additive genetic, and maternal permanent environmental effects that, in general, were chosen based on orders commonly tested for beef cattle in the literature (Boligon et al., 2010; Baldi et al., 2010a).

The structure of residual variances was modeled considering 1 class (homogeneous) to 6 classes of heterogeneity. The age classes used were: CL1, for homogeneous; CL2, 60-149 and 150-819 days; CL3, 60-149, 150-299, and 300-819 days; CL4, 60-149, 150-299, 300-499, and 500-819 days; CL5, 60-149, 150-299, 300-419, 420-499, and 500-819 days; CL6, 60-149, $150-299,300-419,420-499,500-649$, and 650-819 days. Here, CLm is the modeling of heterogeneity of variance, where $m$ represents the number of classes.

The models with different orders of adjustments for the polynomials were compared by the criterion maximum of the logarithm of the likelihood function $(\operatorname{lnL})$, Akaike's information (AIC), Schwarz's Bayesian information (BIC), condition number (CN), which consists in the ratio of the highest to the smallest eigenvalue of the correlation matrix and for the LRT.

The statistics $\operatorname{lnL}$, AIC, and BIC were obtained using the Wombat software (Meyer, 2007). AIC and BIC impose penalties in accordance with the number of parameters to be estimated and are defined as follows:

$$
\begin{array}{cc}
\mathrm{AIC}=-2 \ln \mathrm{L}+2 \mathrm{p}, & \text { (Equation 3) } \\
\mathrm{BIC}=-2 \ln \mathrm{L}+\mathrm{p} \ln [\mathrm{N}-\mathrm{r}(\mathrm{X})] & \text { (Equation 4) }
\end{array}
$$

where $-2 \ln L$ is the deviance of the model, $p$ is the number of estimated parameters, $N$ is the number of observations, $r(X)$ the position of the incidence matrix of the model fixed effects, and $\ln L$ is the maximum of the logarithm of the likelihood function.

The LRT statistic was calculated by the following formula: $\mathrm{LRT}_{\mathrm{ij}}=2 \ln \mathrm{L}_{\mathrm{i}}-2 \ln \mathrm{L}_{\mathrm{j}}$, where $\ln L_{i}$ is the maximum for the likelihood function for the complete model $i$, and $\ln L_{j}$ the maximum of likelihood function for the reduced model $j$. The LRT estimate was compared with the value of the chi-square $\left(\chi^{2}\right)$ tabulated, with $v$ degrees of freedom, and significance 
level of $1 \%$, where $v$ is the difference between the numbers of estimated parameters by the complete and reduced models (nested). The conclusions were drawn as follows: if LRT > $\chi_{\text {tab(n:0.01) }}^{2}$ the test is significant and the complete model provides better adjustment in relation to the reduced model. The null hypothesis tested was that the complete and reduced models did not differ from each other.

In matrix notation, the model with its respective assumptions can be described as:

$$
\mathrm{y}=\mathrm{X} \beta+\Phi_{1} \mathrm{~d}+\Phi_{2} \mathrm{~m}+\Phi_{3} \mathrm{mp}+\Phi_{4} \mathrm{p}+\mathrm{e}
$$

As the vector $y$ is composed sequentially by age within the individual, it is possible to get the following structure of means and variances:

$$
E\left[\begin{array}{c}
y \\
d \\
m \\
m p \\
p \\
e
\end{array}\right]=\left[\begin{array}{c}
X \beta \\
0 \\
0 \\
0 \\
0 \\
0
\end{array}\right], V\left[\begin{array}{c}
d \\
m \\
m p \\
p \\
e
\end{array}\right]=\left[\begin{array}{ccccc}
\mathrm{A} \otimes k_{d} & 0 & 0 & 0 & 0 \\
0 & \mathrm{~A} \otimes k_{m} & 0 & 0 & 0 \\
0 & 0 & I_{N m} \otimes k_{m p} & 0 & 0 \\
0 & 0 & 0 & I_{N d} \otimes k_{p} & 0 \\
0 & 0 & 0 & 0 & \mathrm{R}
\end{array}\right]
$$

where $y$ is the vector of observations; $\beta$ is the vector of fixed effects that contains the coefficients of fixed regression; $d$ is the vector of random regression additive genetic direct coefficients; $m$ is the vector of random regression additive genetic maternal coefficients; $m p$ is the vector of random regression of maternal permanent environmental coefficients; $p$ is the vector of random regression of permanent environmental direct coefficients; $e$ is the random residual vector; $X, \Phi_{d}, \Phi_{m}, \Phi_{m p}$, and $\Phi_{p}$ are the incidence matrices for the polynomial coefficients of the fixed effects, direct additive genetic, maternal additive genetic, maternal permanent environmental, and direct permanent environmental, respectively; $K_{d}, K_{m}, K_{m p}$, and $K_{p}$ are matrices of (co)variances among the direct additive genetic random regression coefficients, maternal additive genetic, maternal permanent environmental, and direct permanent environmental, respectively; $A$ is the numerator relationship matrix; $I_{N d}$ is the identity matrix of dimension $d$ (number of animals with record); $I_{N m}$ is the identity matrix of dimension $m$ (number of dams with calves with record); $R$ is the diagonal matrix of residual variances; and $\otimes$ is the direct product operator.

The covariance between direct additive genetic effects and the maternal additive genetic effects for both MTM and RRM was assumed to be equal to zero.

To enable the comparison of the residual variances obtained in MTM and RRM, the residual variance used in RRM was a composed residual variance, calculated by the sum of the variance of permanent environmental direct and the residual $\left(\mathrm{R}=\Phi_{\mathrm{p}} \mathrm{K}_{\mathrm{p}} \Phi_{\mathrm{p}}{ }^{\prime}+\mathrm{I} \sigma_{\mathrm{e}}^{2}\right)$, thus equivalent to the residual variance obtained by MTM. This calculation is important because it is equivalent, in an RRM, to the residual variance estimated for MTM (Menezes, 2010).

\section{RESULTS AND DISCUSSION}

According to the LRT used in single-trait analysis, the difference between the complete model (M1) and the model containing the direct additive genetic and maternal additive genetic (M2) effects was significant at all ages, excepting W550 (Table 4). These results indicated that the influence of maternal effects continues even after the lactation stage of the animals, and that the inclusion of these effects in the model is needed. Sarmento et al. (2003) 
stated that the maternal environment can influence the calf in pre- and postnatal care, where even the effect can be changed with the management of the animals. Meyer et al. (1993), working with Hereford and Wokalup cattle, reported that maternal effects influenced from birth to 600 days of age.

\begin{tabular}{|c|c|c|c|}
\hline \multicolumn{4}{|c|}{ Change of estimate $-2 \ln L^{1}$} \\
\hline Weights & M1-M2 & M1-M3 & M2-M3 \\
\hline W100 & $7.25 * *$ & $16.70^{* *}$ & $9.45^{* *}$ \\
\hline W205 & $4.66^{*}$ & $19.91 * *$ & $15.25 * *$ \\
\hline W365 & $6.31 *$ & $8.37 *$ & $2.07^{\mathrm{ns}}$ \\
\hline W450 & $8.92 * *$ & $5.93^{\mathrm{ns}}$ & $3.02^{\mathrm{ns}}$ \\
\hline W550 & $1.97^{\mathrm{ns}}$ & $2.16^{\mathrm{ns}}$ & $0.19^{\mathrm{ns}}$ \\
\hline W730 & $5.99 *$ & $0.01^{\mathrm{ns}}$ & $0.01^{\mathrm{ns}}$ \\
\hline
\end{tabular}

The same results were not observed in comparison between M1 and the reduced model (M3) and between M2 and M3, where there were significant differences for ages W100, W205, and W365 in M1 and M3, and for W100 and W205 in M2 and M3. The results indicated that maternal effects affect animals mainly in the period from birth to weaning. Meyer (2003), working with Angus females using RRM, obtained estimates of maternal heritability increasing from birth to approximately 200 days of age and gradually decreasing to zero close to 600 days of age.

Several studies in beef cattle have demonstrated the importance of including maternal effects in the analysis (Meyer et al., 1993; Baldi et al., 2010b; Nobre et al., 2009; Menezes, 2010). Meyer (1997) reported that the models that rule out maternal effects lead to overestimates of direct heritability. Thus, it would be recommended to consider the maternal effects on the genetic evaluation model to obtain more accurate genetic parameters for weights after weaning in MTM.

The choice of the order of the polynomial of the fixed regression curve to model the trajectory of growth using RRM was made based on the coefficient of determination. The increase in order of the polynomial of the fixed curve did not result in significant improvement of the coefficient of determination, and therefore, a third-order polynomial was chosen to model the animal growth curve (Figure 2).

The maximum $\operatorname{lnL}$ values, in general, were lower in less parameterized models; however, some models with more parameters displayed lower values of $\mathrm{lnL}$. Regarding AIC and BIC criteria, there was a tendency of lower values in models more parameterized, but the increase in the number of parameters did not always produce more appropriate models. CN showed, in general, higher values with increase in order of polynomials, i.e., multicollinearity increased with order of the polynomial (Table 5).

Two models were more fitted according to the statistical criteria adopted. The model Leg3633 1, with 40 parameters, was the most appropriate according to the $\operatorname{lnL}$ criterion and LRT, which allowed determining the significant difference with regard to the quantity of parameters. Therefore, the test indicated that the most parameterized model, Leg3633_1, with 40 
parameters, differed statistically $(\mathrm{P}<0.01)$ from the other, i.e., the complete model was more suitable in relation to the reduced model. However, the best model for the other criteria (AIC, BIC, and CN) was Leg3333_1, with 25 parameters, which showed lower values with these criteria. Jamrozik and Schaeffer (2002), in evaluating different RRM to estimate covariance functions for test-day milk production affirmed that different criteria classify the models differently and that it is still unclear which statistical criterion is more suitable.

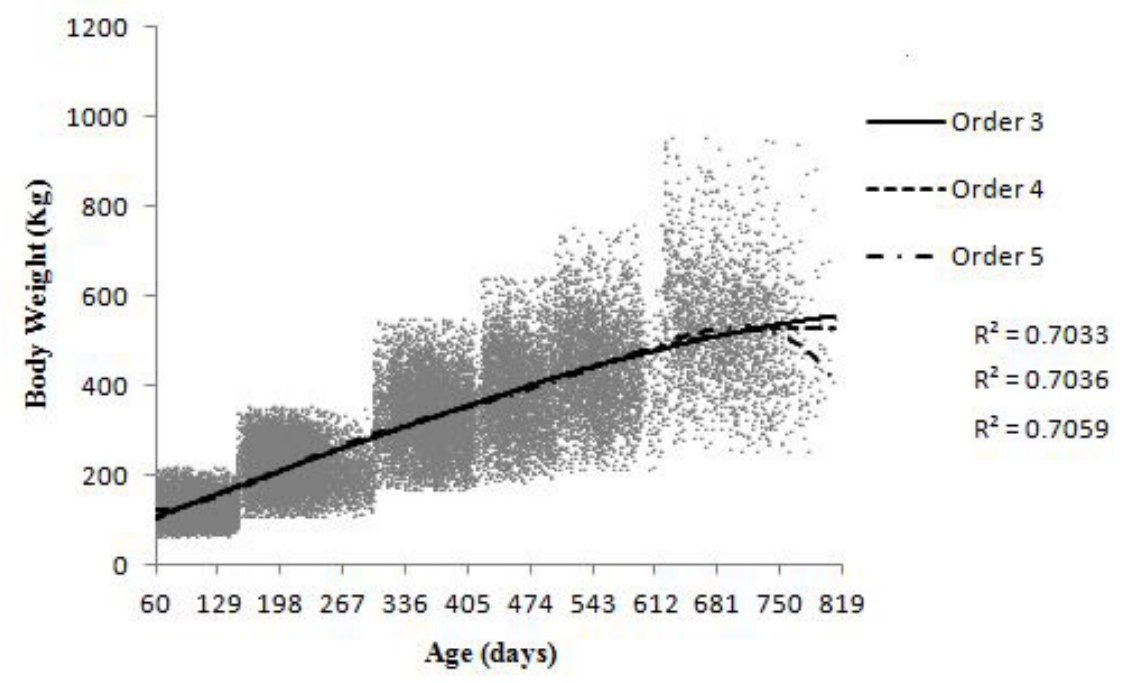

Figure 2. Behavior of the fixed regression curve in the trajectory of growth in different orders of polynomials.

Table 5. Order of polynomial.

\begin{tabular}{|c|c|c|c|c|c|c|c|c|c|c|}
\hline Model & $\mathrm{k}_{\mathrm{d}}$ & $\mathrm{k}_{\mathrm{p}}$ & $\mathrm{k}_{\mathrm{m}}$ & $\mathrm{k}_{\mathrm{mp}}$ & $\mathrm{N}_{\mathrm{p}}$ & $\ln \mathrm{L}$ & LRT & $\mathrm{AIC}$ & $\mathrm{BIC}$ & $\mathrm{CN}$ \\
\hline Leg3333_1 & 3 & 3 & 3 & 3 & 25 & $-122,368.328$ & $1,148.70 * *$ & $-122,393.328$ & $-122,496.294$ & 111.37 \\
\hline Leg4333_1 & 4 & 3 & 3 & 3 & 29 & $-122,104.783$ & $621.61 * *$ & $-122,133.783$ & $-122,253.224$ & 497.04 \\
\hline Leg5333_1 & 5 & 3 & 3 & 3 & 34 & $-121,854.781$ & $121.61 * *$ & $-121,888.781$ & $-122,028.816$ & 738.64 \\
\hline Leg3433_1 & 3 & 4 & 3 & 3 & 29 & $-122,135.619$ & $683.28 * *$ & $-122,164.619$ & $-122,284.061$ & 201.17 \\
\hline Leg3533_1 & 3 & 5 & 3 & 3 & 34 & $-121,978.672$ & $369.39 * *$ & $-122,012.672$ & $-122,152.707$ & 216.70 \\
\hline Leg3633_1 $1^{\text {a }}$ & 3 & 6 & 3 & 3 & 40 & $-121,793.978$ & - & $-121,833.978$ & $-121,998.725$ & 301.45 \\
\hline Leg3323_1 & 3 & 3 & 2 & 3 & 22 & $-122,327.717$ & $1,067.48 * *$ & $-122,349.717$ & $-122,440.328$ & 202.27 \\
\hline Leg3343_1 & 3 & 3 & 4 & 3 & 29 & $-122,211.915$ & $835.87 * *$ & $-122,240.915$ & $-122,360.357$ & 188.20 \\
\hline Leg3332_1 & 3 & 3 & 3 & 2 & 22 & $-122,328.092$ & $1,068.23 * *$ & $-122,350.092$ & $-122,440.702$ & 201.41 \\
\hline Leg3342_1 & 3 & 3 & 4 & 2 & 26 & $-122,229.141$ & $870.33 * *$ & $-122,255.141$ & $-122,362.227$ & 173.61 \\
\hline Leg3344_1 & 3 & 3 & 4 & 4 & 33 & $-122,275.415$ & $962.874 * *$ & $-122,308.415$ & $-122,444.331$ & 163.88 \\
\hline Leg3333_1 & 3 & 3 & 3 & 3 & 25 & $-122,368.328$ & $595.09 * *$ & $-122,393.328$ & $-122,496.294$ & 111.37 \\
\hline Leg3333_2 & 3 & 3 & 3 & 3 & 26 & $-122,310.915$ & $480.26^{* *}$ & $-122,336.915$ & $-122,444.001$ & 61.68 \\
\hline Leg3333_3 & 3 & 3 & 3 & 3 & 27 & $-122,305.438$ & $469.31 * *$ & $-122,332.438$ & $-122,443.642$ & 63.93 \\
\hline Leg3333_4 & 3 & 3 & 3 & 3 & 28 & $-122,337.228$ & $532.88 * *$ & $-122,365.228$ & $-122,480.551$ & 64.86 \\
\hline Leg3333_5 & 3 & 3 & 3 & 3 & 29 & $-122,256.278$ & $370.99 * *$ & $-122,285.278$ & $-122,404.720$ & 65.74 \\
\hline Leg3333_6 ${ }^{\text {b }}$ & 3 & 3 & 3 & 3 & 30 & $-122,070.784$ & - & $-122,100.784$ & $-122,224.344$ & 64.83 \\
\hline
\end{tabular}

Legk $\mathrm{k}_{\mathrm{p}} \mathrm{k}_{\mathrm{m}} \mathrm{k}_{\mathrm{mp}-} \mathrm{r}$ : order of covariance; $\mathrm{k}_{\mathrm{d}}=$ direct additive genetic effects; $\mathrm{k}_{\mathrm{p}}=$ direct permanent environmental; $\mathrm{k}_{\mathrm{m}}=$ maternal additive genetic; $\mathrm{k}_{\mathrm{mp}}=$ maternal permanent environmental; $\mathrm{r}=$ structure of residual variances; $\mathrm{N}_{\mathrm{p}}=$ number of parameters; $\operatorname{lnL}=$ maximum log-likelihood function; $\mathrm{LRT}=$ likelihood ratio test; $\mathrm{AIC}=$ Akaike's information criterion; $\mathrm{BIC}=$ Schwarz's Bayesian information criterion, $\mathrm{CN}=$ number condition criterion. Values in bold indicate the best model based on $\operatorname{lnL}, \mathrm{AIC}, \mathrm{BIC}$, and $\mathrm{CN}$. ${ }^{\mathrm{a}}$ Complete homogeneous model or more parameterized. ${ }^{\mathrm{b}}$ Complete heterogeneous model or more parameterized. **Significant at $1 \%$ probability. 
Legarra et al. (2004) stated that more parsimonious models are preferred because of the smaller computational demands and susceptibility to numerical errors. Thus, the model Leg3333_1, with 25 parameters, was chosen for modeling the trajectory of growth of animals and to obtain the (co)variance components and genetic parameters, since it is more parsimonious and yields estimates closer to those found in multi-trait analysis.

When classes of heterogeneity of residual variances were modeled, the homogeneous model produced the worst fit according to the criteria $\operatorname{lnL}$, LRT, and $\mathrm{CN}$, indicating different behavior of the residual variance during the individuals' growth. Similar results were obtained by Baldi et al. (2010a) and Sarmento et al. (2010a,b), who suggested the use of heterogeneity of residual variances in working with Canchim beef cattle and Santa Inês sheep, respectively. However, by other criteria (AIC and BIC), the model that considers homogeneity of residual variance was the most appropriate and then the most indicated to model the trajectory of growth of Simmental beef cattle.

Furthermore, the inclusion of classes of residual variances produces an increase in direct additive genetic variance, generating estimates of heritability much higher and divergent from those commonly found in the literature for growth traits in beef cattle (Marques et al., 1999; Krejcová et al., 2007; Baldi et al., 2010a,b; Menezes, 2010). Therefore, we chose the model that considered homogeneity of variance, despite not having been the most appropriate with all criteria ( $\operatorname{lnL}, \mathrm{LRT}$, and NC). Another reason for choosing this model is because it is more parsimonious and provides estimates of heritability (genetic parameters) more realistic and closer to those found in the literature.

As can be observed in Figure 3, there was an increase in phenotypic variance $\left(\sigma^{2}\right)$ in relation to the age of the animals for both MTM and RRM. This increase was mainly attributed to the progression of direct additive genetic variance $\left(\sigma_{\mathrm{d}}^{2}\right)$ along the growth curve, and also by the fact that at older ages, weights are usually of greater magnitude, due to scale effect. Similar results were reported by Marques et al. (1999), who worked with the Simmental beef cattle in MTM and observed crescent direct additive genetic variances. Baldi et al. (2010a) in their study with Canchim beef cattle observed an increase in these variances as of 18 months old and of the same magnitude in both MTM and RRM analysis.

Estimates of maternal genetic variances $\left(\sigma_{\mathrm{m}}^{2}\right)$ were, in general, divergent in MTM and RRM (Figure 3). From 100 to 205 days of age, there was a slight increase for MTM and marked decrease in RRM. The growth in MTM is expected because of the greater maternal influence during this period; however, the decrease in RRM is not. This decrease can be brought about by problems that RRM pose in the adjustment of the polynomial function at the end of the age range to be able to estimate (co)variance components not consistent with biological reality. Starting at 205 days of age, a decrease in MTM was observed up to 550 days of age; in contrast, RRM demonstrated an increase in estimates in this interval. Starting at this age, a prominent growth was observed in both models.

Divergent results in MTM were reported by Marques et al. (1999), who observed a slight and constant increase during the growth curve. As for the RRM, Nobre et al. (2003) reported estimates of maternal genetic variance with constant growth from birth to mature age in Nellore beef cattle.

Regarding the maternal permanent environmental effect $\left(\sigma_{m p}^{2}\right)$, the estimates were divergent in both models, with a more acute increase in RRM, especially after 550 days of age, which probably occurred due to the small number of records in that period (Figure 3). Menezes 

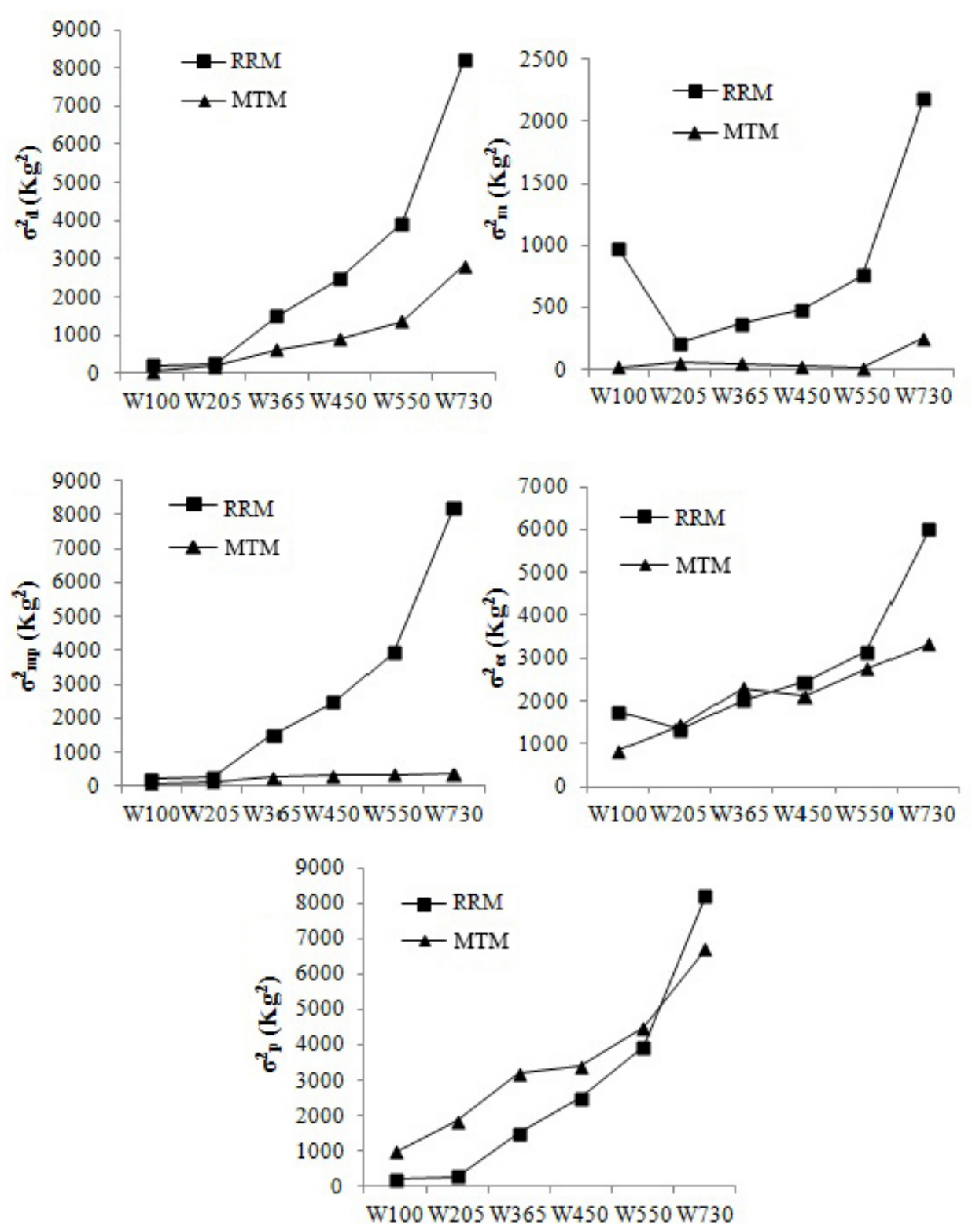

Figure 3. Mean of estimates of direct genetic variance $\left(\sigma^{2}{ }_{d}\right)$, maternal genetic $\left(\sigma^{2}{ }_{m}\right)$, maternal permanent environmental $\left(\sigma_{\mathrm{mp}}^{2}\right)$, composed residual $\left(\sigma^{2}{ }_{\mathrm{ec}}\right)$, and phenotypic $\left(\sigma_{\mathrm{p}}^{2}\right)$ obtained by multi-trait $(\mathrm{MTM})$ and random regression (RRM) models for the weights at 100 (W100), 205 (W205), 365 (W365), 450 (W450), 550 (W550), and 730 (W730) days of age.

(2010) obtained an abrupt increase in estimates of maternal permanent environmental effect, as of 480 days in Tabapuã beef cattle. However, another important point possible accounting for these estimates was the small number of calves per dam observed, which was on average 
1.45. Pelicioni et al. (2003) worked with Guzerá beef cattle, with an average number of calves per dam between 1.2 and 1.5 from birth to mature age, and asserted that it was not possible to estimate the maternal permanent environmental effect. Tanaka et al. (2009) and Bittencourt et al. (2002) also could not estimate the maternal permanent environmental effect in Guzerá beef cattle in their study with the average number of calves per dam less than 2.

Maniatis and Pollott (2003), in their work with Suffolk sheep, affirmed that data with limited structure may be the cause of biologically impossible estimates and that they would need several generations of records and the largest possible amount of relationship information among animals and their dams to obtain more accurate estimates.

In general, estimates of composed residual variances $\left(\sigma^{2}{ }_{\text {ec }}\right)$ were of the same magnitude in both models. In MTM, the composed residual variances increased up to 365 days, when a slight decrease was observed until 450 days. Starting at this age, a new and more marked increase in these variances occurred (Figure 3). Baldi et al. (2010b) and Menezes (2010) obtained linear increasing in the estimates of residual variances along the growth trajectory. In RRM, the same behavior reported in MTM was observed. However, a slight decline was observed in the interval of 100 to 205 days of age. This was possibly due to the large number of records near the age of 205 days, relative to 100 days, resulting in less error. Regarding RRM, results outside biological reality were diagnosed as of 550 days of age and were likely because of the small number of records available in that period, as previously described.

Direct heritabilities $\left(\mathrm{h}_{\mathrm{d}}^{2}\right)$ were similar in trend using MTM and RRM for weights at W100, W205, W365, W450, W550, and W730 days of age (Table 6). However, in general, the heritability estimates obtained by RRM were higher than those estimates obtained by MTM. Continued growth of this heritability was somewhat observed, except for the slight decrease at W730 for RRM, possibly because RRM provides less appropriate adjustments when there are few weight records.

Table 6. Estimates of heritability and variance, in relation to the total phenotypic variance, obtained for MTM and RRM (in parentheses) by the model Leg3333_1 for weights at 100 (W100), 205 (W205), 365 (W365), 450 (W450), 550 (W550), and 730 (W730) days of age.

\begin{tabular}{lcccc}
\hline Weights & $\mathrm{h}_{\mathrm{d}}{ }^{*}$ & $\mathrm{~h}_{\mathrm{m}}{ }^{*}$ & $\mathrm{mp}^{2 *}$ & $\mathrm{ec}^{2 *}$ \\
\hline W100 & $0.04(0.16)$ & $0.01(0.08)$ & $0.09(0.01)$ & $0.86(0.75)$ \\
W205 & $0.11(0.14)$ & $0.01(0.11)$ & $0.08(0.06)$ & $0.80(0.69)$ \\
W365 & $0.20(0.36)$ & $0.00(0.09)$ & $0.08(0.08)$ & $0.72(0.47)$ \\
W450 & $0.27(0.42)$ & $0.01(0.08)$ & $0.10(0.09)$ & $0.62(0.41)$ \\
W550 & $0.31(0.46)$ & $0.00(0.09)$ & $0.08(0.09)$ & $0.61(0.36)$ \\
W730 & $0.42(0.45)$ & $0.03(0.12)$ & $0.06(0.10)$ & $0.49(0.33)$ \\
\hline
\end{tabular}

*Mean of two-trait analysis for MTM. $\mathrm{h}_{\mathrm{d}}{ }_{\mathrm{f}}=$ direct heritability; $\mathrm{h}_{\mathrm{m}}^{2}=$ maternal heritability; $\mathrm{mp}^{2}=$ proportion of maternal permanent environmental variance; $\mathrm{ec}^{2}=$ composed residual variance.

In MTM, the estimates were similar to those obtained by Marques et al. (2000) with values of $\mathrm{h}_{\mathrm{d}}{ }_{\mathrm{d}}$ for $\mathrm{W} 100, \mathrm{~W} 205, \mathrm{~W} 365$, and $\mathrm{W} 550$, respectively equal to $0.08,0.13,0.19$, and 0.24 in Simmental beef cattle. For RRM, the heritabilities found were generally higher than those reported by Krejcová et al. (2007), who used a third-order model for the direct additive genetic effect on Simmental beef cattle and found values of direct heritabilities equal to 0.07, $0.15,0.12$, and 0.07 in age intervals that included, respectively, 100, 205, 365, and 450 days.

Maternal heritability values $\left(\mathrm{h}_{\mathrm{m}}^{2}\right)$ obtained in this study were of low magnitude and had generally the same behavior, increasing up to weaning with a slight decrease up to 365 
days, and then, new rise until mature age (Table 6). This unexpected rise after 365 days of age can be explained by the small number of records observed after 1 year old. Divergent results in relation to this study were obtained by Baldi et al. (2010a) and Boligon et al. (2009), who obtained maximum estimates at birth, abrupt decrease after birth, increase up to 400 days of age, and a new gradual decrease until the end of the growth trajectory in Canchim and Nelore beef cattle, respectively.

Just as in the estimates of direct heritabilities, those estimated via RRM were higher. Menezes (2010) obtained similar results in his study with Tabapuã beef cattle, where maternal heritability estimates, in general, were higher in RRM compared to MTM.

Estimates of maternal permanent environmental variance $\left(\mathrm{mp}^{2}\right)$, as a proportion of phenotypic variance, were generally similar in the 2 models (Table 6). However, the estimates for MTM were slightly higher in the beginning of the growth curve and slightly lower at the end of it.

Unlike the results obtained in this study, Baldi et al. (2010a) obtained estimates of maternal permanent environmental variances higher in MTM when compared to random regression. Although, Menezes (2010) and Boligon et al. (2009) obtained divergent results and did not observe differences between the estimates in these 2 models, and in both results there were also gradual decreases in these estimates from weaning and birth, respectively.

Regarding the composed residual variance $\left(\mathrm{ec}^{2}\right)$ as a proportion of phenotypic variance, the results obtained by MTM were superior to those by RRM throughout the growth trajectory of animals (Table 6), which can be indicative of the superior quality of adjustment for RRM in relation to MTM (Menezes, 2010). Similar results were obtained by Menezes (2010) in Tabapuã beef cattle for $\mathrm{ec}^{2}$ estimates, which were slightly higher in MTM.

Excepting the correlations between W100 and the other ages via RRM whereupon they were negative and of low magnitude, the results for the direct additive genetic correlations, for both RRM and MTM, are in the range of values seen in the literature (Sakaguti et al., 2003; Dias et al., 2006; Baldi et al., 2010a,b; Menezes, 2010; Sousa Júnior et al., 2010). Estimates of direct additive genetic correlations obtained for the MTM and RRM were generally high and positive, indicating that part of the action of additive genes which influences one trait also influences the other (Table 7).

Table 7. Estimates of direct additive genetic correlations (above diagonal) and phenotypic (below diagonal) obtained via MTM and RRM (in parentheses) by the model Leg3333_1 for weights at 100 (W100), 205 (W205), 365 (W365), 450 (W450), 550 (W550), and 730 (W730) days of age.

\begin{tabular}{lcccccc}
\hline Weight & W100 & W205 & W365 & W450 & W550 \\
\hline W100 & - & $0.99(0.05)$ & $0.92(-0.42)$ & $0.66(-0.47)$ & $1.00(-0.48)$ & $0.82(-0.42)$ \\
W205 & $0.69(0.24)$ & - & $0.99(0.86)$ & $1.00(0.78)$ & $0.96(0.68)$ & $1.00(0.46)$ \\
W365 & $0.34(0.10)$ & $0.53(0.58)$ & - & $0.94(0.99)$ & $0.93(0.94)$ & $0.83(0.78)$ \\
W450 & $0.42(0.04)$ & $0.53(0.54)$ & $0.91(0.80)$ & - & $0.98(0.98)$ & $0.92(0.86)$ \\
W550 & $0.30(-0.02)$ & $0.46(0.45)$ & $0.81(0.76)$ & $0.91(0.85)$ & - & $1.00(0.94)$ \\
W730 & $0.19(-0.11)$ & $0.40(0.23)$ & $0.61(0.58)$ & $0.74(0.72)$ & $0.81(0.85)$ & - \\
\hline
\end{tabular}

However, correlations obtained with MTM were, in general, superior to those with RRM. Similar results were reported by Iwaisaki et al. (2005) and Menezes (2010), who worked, respectively, with Gelbvieh and Tabapuã breeds and obtained estimates of direct additive genetic correlations superior in MTM, when compared to RRM. 
The results of estimates among W100 and the other estimated ages can probably be explained by problems arising from the polynomial function, since correlations between these measures, predominantly positive, are expected because the weight of the animals is the result of the cumulative sum of the gain throughout life, which creates a structural dependence between them.

Regarding the phenotypic correlations between the weights studied, they tended to be generally higher at closer ages. However, the same behavior was not observed for the correlations between W100 and the other ages, probably as a consequence of the behavior of direct genetic correlations, where such situation was also observed (Table 7). Sarmento et al. (2006) assessed growth traits of Santa Inês' sheep breed and reported an increase in the magnitude of correlations, when the ages are close.

The phenotypic correlations obtained in MTM were of higher magnitude in relation to the RRM (Table 7), which differs from the results found by Sarmento et al. (2006), who observed smaller phenotypic correlations for MTM.

The genetic maternal correlations showed contrasting behavior compared to those normally seen in the literature (Albuquerque and Meyer, 2001; Baldi et al., 2010a,b; Menezes, 2010). These authors obtained similar estimates, positive and of high magnitude, in comparing MTM and RRM. In contrast, we observed that the values found for MTM were superior in relation to RRM (Table 8).

Table 8. Estimates of maternal genetic correlations (above diagonal) and maternal permanent environmental (below diagonal), obtained via MTM and RRM (in parentheses) by the model Leg3333-1 for the weights at 100 (W100), 205 (W205), 365 (W365), 450 (W450), 550 (W550), and 730 (W730) days of age.

\begin{tabular}{lcccrrr}
\hline Weight & W100 & W205 & W365 & W450 & W550 & W730 \\
\hline W100 & - & $1.00(0.97)$ & $1.00(0.77)$ & $1.00(0.55)$ & $-1.00(0.23)$ & $-1.00(-0.23)$ \\
W205 & $1.00(1.00)$ & - & $-1.00(0.90)$ & $-0.19(0.74)$ & $-1.00(0.47)$ & $-0.96(0.02)$ \\
W365 & $0.88(0.95)$ & $0.89(0.96)$ & - & $0.08(0.96)$ & $1.00(0.80)$ & $-1.00(0.45)$ \\
W450 & $0.69(0.88)$ & $0.67(0.90)$ & $1.00(0.98)$ & - & $1.00(0.94)$ & $-1.00(0.69)$ \\
W550 & $0.82(0.74)$ & $1.00(0.76)$ & $0.85(0.91)$ & $1.00(0.97)$ & - & $0.99(0.89)$ \\
W730 & $1.00(0.41)$ & $1.00(0.44)$ & $1.00(0.66)$ & $1.00(0.79)$ & $1.00(0.92)$ & - \\
\hline
\end{tabular}

Elevated values were observed especially among the early ages, and according to Boligon et al. (2010), this indicates that maternal effects for these ages are controlled by the same genes. In addition, estimates of negative correlations were observed in both MTM and RRM, indicating a behavior outside biological reality, since positive and high magnitude correlations are expected, as previously explained.

Estimates of maternal permanent environmental correlations in both MTM and RRM were, in general, of high magnitude and positive, and most of them equal to unity (Table 8). For MTM, a random behavior was observed along the growth curve, near unity among the ages at the beginning and the end of the curve, and slightly lower at ages located in the middle of the trajectory, confirming the results reported by Menezes (2010), who worked with Tabapuã beef cattle and obtained positive and high magnitude estimates of maternal permanent environmental correlations.

In the meantime, RRM correlations tended to be smaller as the difference in ages grew. These results are in accordance with those obtained by Dias et al. (2006) in Tabapuã beef cattle and in contrast with those reported by Baldi et al. (2010a), who obtained estimates of 
maternal permanent environmental correlations, close to unity in Canchim beef cattle.

Based on the results of this study, we can indicate the use of RRM in genetic evaluation of breeding programs of Simmental beef cattle. We may point out the fact that RRM does not require pre-adjustment of weights at standard ages and a possible gain in accuracy of RRM. Meyer (2004), working with simulated data for beef cattle using MTM and RRM, concluded that RRM are more accurate than MTM due to better modeling of variance components and genetic parameters, beyond the elimination of pre-adjusted ages in RRM.

A third-order RRM for the fixed regression curve and for random effects, direct additive genetic, maternal genetic effect, maternal permanent environmental effect, and direct permanent environmental was sufficient to model the weight variance structures in the growth trajectory of animals.

Due to the possibility of implementation and lack of requirement for pre-adjustment weights at standard ages, RRM can be recommended in the genetic evaluation of Simmental beef cattle in Brazil.

\section{ACKNOWLEDGMENTS}

Research supported by CNPq, CAPES, and FAPEMIG. Associação Brasileira de Criadores das Raças Simental e Simbrasil (ABCRSS) provided the data used in this research.

\section{REFERENCES}

Albuquerque LG and Meyer K (2001). Estimates of covariance functions for growth from birth to 630 days of age in Nelore cattle. J. Anim. Sci. 79: 2776-2789.

Albuquerque LG and El Faro L (2008). Comparações entre os valores genéticos para características de crescimento de bovinos da raça Nelore preditos com modelos de dimensão finita ou infinita. Rev. Bras. Zootec. 37: 238-246.

Baldi F, Albuquerque LG and Alencar MM (2010a). Random regression models on Legendre polynomials to estimate genetic parameters for weights from birth to adult age in Canchim cattle. J. Anim. Breed. Genet. 127: 289-299.

Baldi F, Alencar MM and Albuquerque LG (2010b). Estimativas de parâmetros genéticos para características de crescimento em bovinos da raça Canchim utilizando modelos de dimensão finita. Rev. Bras. Zootec. 39: 2409-2417.

Bittencourt TCC, Rocha JCMC, Lôbo RB and Bezerra LF (2002). Estimação de componentes de (co)variâncias e predição de DEP's para características de crescimento pós-desmama de bovinos da raça Nelore, usando diferentes modelos estatísticos. Arq. Bras. Med. Vet. Zootec. 54: 303-308.

Boligon AA, Mercadante MEZ, Baldi F, Lôbo RB, et al. (2009). Multi-trait and random regression mature weight heritability and breeding value estimates in Nelore cattle. S. Afr. J. Anim. Sci. 39: 145-148.

Boligon AA, Mercadante ME, Forni S, Lobo RB, et al. (2010). Covariance functions for body weight from birth to maturity in Nellore cows. J. Anim. Sci. 88: 849-859.

Dias LT, Albuquerque LG, Tonhati H and Teixeira RA (2006). Estimação de parâmetros genéticos para peso do nascimento aos 550 dias de idade para animais da raça Tabapuã utilizando-se modelos de regressão aleatória. Rev. Bras. Zootec. 35: 1915-1925.

Henderson CR Jr (1982). Analysis of covariance in the mixed model: higher-level, nonhomogeneous, and random regressions. Biometrics 38: 623-640.

Iwaisaki H, Tsuruta S, Misztal I and Bertrand JK (2005). Genetic parameters estimated with multitrait and linear splinerandom regression models using Gelbvieh early growth data. J. Anim. Sci. 83: 757-763.

Jamrozik J and Schaeffer L (2002). Bayesian Comparison of Random Regression Models for Test-Day Yields in Dairy Cattle. Proceedings of the World Congress on Genetic Applied to Livestock Production, Montpellier.

Krejcová H, Mielenz N, Pribyl J and Schüler L (2007). Estimation of Genetic Parameters for Daily Gains of Bulls with Multi-Trait and Random Regression Models. Arch. Tierz. Dummerstorf 50: 37-46.

Laird NM and Ware JH (1982). Random-effects models for longitudinal data. Biometrics 38: 963-974.

Legarra A, Misztal I and Bertrand JK (2004). Constructing covariance functions for random regression models for growth 
in Gelbvieh beef cattle. J. Anim. Sci. 82: 1564-1571.

Maniatis N and Pollott GE (2003). The impact of data structure on genetic (co)variance components of early growth in sheep, estimated using an animal model with maternal effects. J. Anim. Sci. 81: 101-108.

Marques LFA, Pereira JCC, Oliveira HN, Pereira CS, et al. (1999). Componentes de (co)variância e parâmetros genéticos de características de crescimento da raça Simental no Brasil. Arq. Bras. Med. Vet. Zoot. 51: 363-370.

Marques LFA, Pereira JCC, Oliveira HN, Silva A, et al. (2000). Análise de característica de crescimento da raça Simental. Arq. Bras. Med. Vet. Zootec. 52: 527-533.

Marques LFA, Oliveira HN, Pereira JCC and Silva ALS (2001). Análises uni e bicaráter em características de crescimento da raça Simental. Rev. Bras. Cienc. Vet. 8: 69-72.

Menezes GRO (2010). Uso de Polinômios Segmentados na Modelagem de Dados Longitudinais de Ponderal em Bovinos da Raça Tabapuã. Doctoral thesis. Universidade Federal de Viçosa, Viçosa.

Meyer K (1997). Estimates of genetic parameters for weaning weight of beef cattle accounting for direct-maternal environmental covariances. Livest. Prod. Sci. 52: 187-199.

Meyer K (1999). Estimates of genetic and phenotypic covariance functions for postweaning growth and mature weight of beef cows. J. Anim. Breed. Genet. 116: 181-205.

Meyer K (2003). First estimates of covariance functions for lifetime growth of Angus cattle. Proc. Assoc. Adv. Anim. Breed. Genet. 15: 395-398.

Meyer K (2004). Scope for a random regression model in genetic evaluation of beef cattle for growth. Livest. Prod. Sci. 86: 69-83.

Meyer K (2007). WOMBAT: a tool for mixed model analyses in quantitative genetics by restricted maximum likelihood (REML). J. Zhejiang Univ. Sci. B 8: 815-821.

Meyer K, Carrick MJ and Donnelly BJ (1993). Genetic parameters for growth traits of Australian beef cattle from a multibreed selection experiment. J. Anim. Sci. 71: 2614-2622.

Nobre PR, Misztal I, Tsuruta S, Bertrand JK, et al. (2003). Analyses of growth curves of nellore cattle by multiple-trait and random regression models. J. Anim. Sci. 81: 918-926.

Nobre PRC, Rosa AN and Silva LOC (2009). Genetic evaluation for large data sets by random regression models in Nellore cattle. Arq. Bras. Med. Vet. Zootec. 61: 959-967.

Patterson HD and Thompson R (1971). Recovery of inter-block information when block sizes are unequal. Biometrika 58: 545-554.

Pelicioni LC, Queiroz AS and Albuquerque LG (2003). Estimativas de Parâmetros Genéticos para Pesos ao Nascer e Mensais até 450 dias em Bovinos Guzerá. Arch. Latinoam. Prod. Anim. 11: 34-39.

Sakaguti ES, Silva MA and Quaas RL (2003). Avaliação do crescimento de bovinos jovens da raça Tabapuã, por meio de análise de funções de covariância. Rev. Bras. Zootec. 32: 864-874.

Sánchez JP, Misztal I, Aguilar I and Bertrand JK (2008). Genetic evaluation of growth in a multibreed beef cattle population using random regression-linear spline models. J. Anim. Sci. 86: 267-277.

Sarmento JLR, Pimenta Filho EC, Ribeiro MN and Martins Filho R (2003). Efeitos ambientais e genéticos sobre o ganho em peso diário de bovinos nelore no estado da Paraíba. Braz. J. Anim. Sci. 32: 325-330.

Sarmento JLR, Torres RA, Sousa WH, Pereira CS, et al. (2006). Estimação de parâmetros genéticos para características de crescimento de ovinos Santa Inês utilizando modelos uni e multicaracterísticas. Arq. Bras. Med. Vet. Zootec. 58: 581-589.

Sarmento JLR, Torres RA, Lobô RNB, Albuquerque LG, et al. (2010a). Modelos de regressão aleatória na avaliação genética do crescimento de ovinos da raça Santa Inês. Rev. Bras. Zootec. 39: 1723-1732.

Sarmento JLR, Torres RA, Pereira CS, Souza WH, et al. (2010b). Avaliação genética de características de crescimento de ovinos Santa Inês utilizando modelos de regressão aleatória. Arq. Bras. Med. Vet. Zootec. 58: 68-77.

SAS (2004). SAS Institute Inc. SAS/STAT ${ }^{\circledR} 9.0$ User’s Guide. SAS Campus Drive, Cary.

Silva FG (2011). Estudo da Produção de Leite de Caprinos Utilizando Modelos de Regressão Aleatória, Doctoral thesis. Universidade Federal de Viçosa, Viçosa.

Sousa Júnior SCS, Oliveira SMP, Albuquerque LG, Boligon AA, et al. (2010). Estimação de funções de covariância para características de crescimento da raça Tabapuã utilizando modelos de regressão aleatória. Rev. Bras. Zootec. 39: 1037-1045.

Tanaka ALR, Carvalheiro R, Fries LA and Queiroz SA (2009). Comparação de critérios de seleção para precocidade de crescimento em bovinos da raça Guzerá. Rev. Bras. Zootec. 38: 284-291. 